Revista Destaques Acadêmicos, Lajeado, v. 12, n. 3, 2020. ISSN 2176-3070

DOI: http://dx.doi.org/10.22410/issn.2176-3070.v12i3a2020.2384

http://www.univates.br/revistas

\title{
METODOLOGIAS DE ENSINO E APRENDIZAGEM NO CURSO TÉCNICO EM ENFERMAGEM
}

\author{
Shara Salvador ${ }^{1}$, Edson Moacir Ahlert ${ }^{2}$
}

Resumo: O presente estudo pretende avaliar as percepções de estudantes do Curso Técnico em Enfermagem sobre as metodologias de ensino adotadas em sala de aula, evidenciando na disciplina de Introdução em Enfermagem. Além disso, identificou-se as principais motivações que levaram os estudantes a escolherem o curso de Técnico em Enfermagem. A pesquisa caracteriza-se como descritiva quanto aos objetivos, de levantamento em relação aos procedimentos e quantitativa quanto ao tratamento e análise dos dados. Para tanto, utilizou-se de questionário como instrumento de coleta de dados e a amostra foi de 30 estudantes. A pesquisa foi realizada em 2017, no Curso Técnico em Enfermagem na cidade de Guaporé - RS. Como resultados verificou-se que, na percepção dos estudantes, os métodos e técnicas de ensino considerados mais eficazes para o aprendizado são aulas que envolvam atividades práticas, porém, a aula com apresentação de trabalhos é a metodologia mais utilizada pelos professores. Evidenciou-se que ensinar e aprender vai muito além do que transmitir e reproduzir conhecimentos. Considerando as novas metodologias na Educação, fica compreendido que o professor necessita atuar como mediador, motivar ideias, para que os estudantes se tornem ativos no processo, críticos e reflexivos, evidenciando a prática profissional atual.

Palavras-chave: Metodologias de Ensino e Aprendizagem. Cursos Técnicos. Técnico em Enfermagem.

\section{INTRODUÇÃO}

A presente pesquisa visou avaliar as metodologias de ensino e aprendizagem utilizadas no Curso Técnico em Enfermagem, em Guaporé, na disciplina de Introdução em Enfermagem, segundo semestre de 2017, por meio da percepção dos estudantes matriculados na disciplina.

1 Graduada em Enfermagem. Acadêmica do Curso de Pós-Graduação Lato Sensu-Especialização em Docência na Educação Profissional da Univates.

2 Professor da Univates. Mestre em Ambiente e Desenvolvimento. 
A finalidade deste estudo consiste em verificar quais métodos de ensino que se mostraram mais eficazes em relação à aprendizagem, na percepção dos estudantes do Técnico em Enfermagem, considerando ser a pesquisadora integrante da instituição escolar, e desde o início do curso ter observado o surgimento de questões em torno da necessidade do uso de uma diversidade de metodologias para incrementar a qualidade dos processos de ensino e aprendizagem, para a formação dos profissionais da área de saúde, permitindo assim, a capacitação quanto as suas atribuições, buscando atender ao perfil de habilidades e competências exigidas pelo mercado de trabalho.

Atualmente, para o atendimento das necessidades da área de Saúde, as instituições de educação profissional necessitam preparar seus utentes para o pleno exercício de suas funções mentais, cognitivas e sócio-afetivas, com capacidade de aprender com autonomia e assimilar o crescente número de informações, adquirir novos conhecimentos e habilidades e enfrentar situações novas com dinamismo, flexibilidade e criatividade, compreendendo as bases sociais, econômicas, técnicas, tecnológicas e científicas (BRASIL, 2000).

Conforme Moran (2013) se queremos que os estudantes sejam proativos, precisamos adotar metodologias em que eles se envolvam em atividades cada vez mais complexas, em que tenham que tomar decisões e avaliar os resultados.

Nos dias atuais, há uma grande necessidade que os docentes dos variados níveis de ensino desenvolvam competências profissionais para preparar os estudantes para uma formação crítico social. É preciso, portanto, substituir as formas tradicionais de ensino por metodologias ativas de aprendizagem, e que estas sejam utilizadas de forma eficiente na prática educacional cotidiana. Nesse sentido, há a necessidade de um novo posicionamento dos docentes mediante a escolha "das atividades que vão promover a partilha de conhecimento com o estudante" (CASTANHA et al., 2017, p. 2).

Importante referenciar que a docência na área da saúde geralmente se dá por profissionais que não tem em sua origem profissional na pedagogia, dificultando a aplicabilidade de diferentes metodologias, priorizando muitas vezes o método tradicional, onde o conhecimento e aprendizagem são focados basicamente nas habilidades do professor, com aulas expositivas.

Com base nesse contexto, a presente pesquisa busca responder à seguinte questão: quais as percepções dos estudantes sobre as metodologias de ensino e aprendizagem adotadas pelos seus professores no curso Técnico em Enfermagem? Sendo assim, este estudo tem por objetivo identificar e analisar as percepções dos estudantes sobre as metodologias de ensino adotadas em sala de aula. De modo complementar, buscou-se identificar as principais motivações que levaram os estudantes a escolherem o curso Técnico em Enfermagem e as habilidades que julgam mais importante na formação.

Esta pesquisa tem o objetivo identificar as metodologias de ensino adotadas pelos professores do curso Técnico em Enfermagem de Guaporé 
bem como a percepção dos estudantes sobre o impacto destas metodologias na aprendizagem. Por meio dos resultados deste estudo, pretende-se fomentar discussões para aperfeiçoar o processo de ensino e aprendizagem no curso, com a finalidade de qualificar o aprendizado dos futuros profissionais técnicos em enfermagem.

\section{REFERENCIAL TEÓRICO}

Com a criação de cursos de enfermagem, a profissão foi evoluindo e as escolas de enfermagem acompanharam este processo, tornando-se cada vez mais exigentes para inserir o estudante em uma sociedade cada vez tecnológica.

Na Educação Profissional, a formação do Técnico em Enfermagem vem sofrendo transformações relativas às novas concepções concretizadas por meio das Diretrizes Curriculares Nacionais (DCN) para a Educação Profissional. As DCN passam a estabelecer como concepção orientadora o modelo das competências, que procura desenvolver no futuro trabalhador diversas capacidades (iniciativa, raciocínio, pensamento crítico e empreendedorismo, entre outras) que lhe permitirão transitar e atender suas demandas profissionais, construindo seu itinerário profissional (BRASIL, 1999).

Para Zanotti (1996), a educação tem um papel essencial na construção do futuro da enfermagem. A partir das exigências deste mundo globalizado, em constante mudança, os enfermeiros educadores devem continuamente introduzir novas metas e métodos de ensino para que alcancem as necessidades dos estudantes.

Estratégias de ensino e de aprendizagem, ferramentas de ensino, recursos para o processo ensino e aprendizagem, métodos de ensino, tecnologia educacional ou técnicas pedagógicas são termos que descrevem "o conjunto de métodos e técnicas que são utilizados afins de que o processo de ensino e de aprendizagem se realize com êxito" (MARTINS, 1990, p.182).

O método que o professor utiliza para desenvolver um conteúdo é o instrumento mais importante para alcançar os objetivos a que se propõe. Entretanto, não existe um método pedagógico universal e sim vários recursos ou ferramentas que o professor lança mão para estimular o estudante a aprender.

Desenvolver uma aula ou apresentar um conteúdo está focado no papel principal da escola, que deve introduzir noções de cidadania e ética, estimular habilidades, relacionar com a atualidade, desenvolver independência, estabelecer regras, trocar informações e socializar (OLIVEIRA, 2009).

A Constituição Federal - Lei de Diretrizes e Bases da Educação, estabelece: Independente de serviços prestados para uma instituição pública ou particular, todo educador deve ter como premissa para o desempenho de sua atividade o relevante valor de cada aula ministrada (BRASIL, 1996). 
Machado (2006) afirma que o professor precisa ser criativo, dinâmico, ter capacidade de análise e síntese, ter habilidade para trabalhar em equipe, ter espírito empreendedor, ter carisma e dedicação para aplicar diferentes estratégias pedagógicas.

Libâneo (1994) acrescenta que as exigências práticas da sala de aula requerem princípios básicos para orientar a atividades dos professores. $\mathrm{O}$ ensino precisa ter caráter científico e sistemático, ser compreensível e possível de ser construído, assegurar a relação conhecimento e prática, assentar-se na unidade ensino e aprendizagem, garantir a solidez dos conhecimentos e levar à vinculação trabalho coletivo e particularidade individual.

Sabe-se, atualmente, que a aprendizagem ocorre quando o estudante participa ativamente do processo de construção e reconstrução do conhecimento. Nesta perspectiva, é preciso substituir, nas aulas, as tarefas mecânicas que apelam para a repetição e a memorização, por tarefas que exijam dos estudantes a execução de operações mentais (SILVA, 2002).

Para que esta nova postura de ensinar seja alcançada, o enfermeiro que atua ou deseja atuar como docente necessita conhecer os métodos e técnicas de ensino e de aprendizagem, para então, poder utilizá-los de forma adequada para cada situação.

O significado da palavra método tem origem grega, na reflexão filosófica de Platão e Aristóteles. A acepção da expressão refere-se ao caminho a ser seguido, sendo meta = atrás, em seguida, através; hodos = caminho, método significa o caminho a ser seguido para se atingir determinado fim. Este conceito passa a ser pertinente se considerarmos a Educação para esse fim (MITRE, 2008).

Define-se a metodologia didática como o conjunto de métodos e técnicas de ensino para a aprendizagem. O método é o caminho para chegar a um objetivo, a técnica é o processo de fazer algo, como fazê-lo. A escolha da metodologia de ensino e de aprendizagem é feita de acordo com as condições e circunstâncias do estudante, do professor e do ambiente (SANTOS, 2001).

A essência da metodologia tradicional está na valorização maior do ensino em relação à aprendizagem, desta forma o ensino torna-se um paradigma, o autor na metodologia tradicional é o professor, pois se a metodologia está centrada no ensino, quem importa é quem ensina. Nessa, as características do estudante não são relevantes, pois é o professor o detentor do conhecimento, quem tem a tarefa de transmitir seu conhecimento e avaliar a retenção do mesmo pelo estudante (FREIRE, 1979).

As novas metodologias ou metodologias inovadoras são descritas por Berbel (1998), como tendo base nos princípios do método científico, no qual os estudantes aprendem a aprender, em um ensino integrado e integrador dos conteúdos das diferentes áreas envolvidas, em que precisa mobilizar seus conhecimentos para solucionar problemas contextualizados na realidade da 
sua futura profissão. Cabe ao professor atuar como guia no planejamento e na seleção das melhores estratégias para atingir os objetivos de aprendizado, orientar a execução e, por fim, a verificação do alcance dos objetivos propostos (BERBEL, 1998).

Podemos entender Metodologias Ativas como formas de desenvolver o processo do aprender que os professores utilizam na busca de conduzir a formação crítica de futuros profissionais nas mais diversas áreas. A utilização dessas metodologias pode favorecer a autonomia do estudante, despertando a curiosidade, estimulando tomadas de decisões individuais e coletivas, advindos das atividades essenciais da prática social e em contextos do estudante (MINAYO, 2007).

O seminário e a palestra podem ser utilizados como forma de estimular o estudo aprofundado de um tema, a coleta de informações e experiências, a pesquisa e o conhecimento global do tema, apresenta uma das formas de estudo em grupo utilizado pelos professores, mas de forma mais aprofundada.

O seminário é uma forma de trabalho em grupo, muito utilizada no Ensino Médio, Graduação e Pós-graduação. Esse método "se constrói com base no ensino com pesquisa, realizado em subgrupos, e no debate dos aspectos investigados, de maneira integrada ou complementar, sob a coordenação do professor" (PEREIRA, 2003, p.161).

No seminário, os estudantes podem substituir o lugar do professor, pois agora são eles que irão fazer uma "exposição", explicando um tema ou assunto pré-determinado, onde poderá ocorrer o debate ou discussão dos principais pontos encontrados pela turma. Os seminários e as palestras contribuem na construção da autonomia do estudante, pois os estudantes desenvolvem habilidades de pesquisa, registro, comunicação e argumentação oral (PEREIRA, 2003).

A prática do diálogo em sala de aula permite a possibilidade de transformar uma aula que seria simplesmente de transmissão do conhecimento pronto por parte do educador, a uma aula em que o estudante terá a oportunidade de mostrar o seu conhecimento prévio, associar este as informações trazidas pelo professor e por fim tecer uma relação entre conhecimento e experiências, possibilitando assim o surgimento das perguntas (PEREIRA, 2003).

O grupo como uma forma de metodologia pode apresentar várias definições. Segundo Fernandes (1983), ele é "um sistema com uma estrutura, organização e normas próprias". Na perspectiva de Lopes e Silva (2009), o grupo é um sistema de interdependência entre indivíduos, que se propõem alcançar um objetivo comum e que se regem por um conjunto de normas, para um desenvolvimento mais eficaz.

Ao conceito de grupo está subjacente "a ideia de cooperação e esta está no centro de todos os tipos de organização", que envolvem a aprendizagem 
(FERNANDES, 1983, p. 108). Por isso, a aprendizagem cooperativa e trabalho de grupo, aparecem frequentemente associados.

A estratégia de ensino leitura tutorial é uma intervenção didática com base em leitura compartilhada que tem como objetivo facilitar a compreensão de textos. Nessa técnica, cabe ao professor o papel de facilitador durante o processo de leitura e compreensão, valorizando a reflexão interdisciplinar (MOREIRA; RIBEIRO, 2016). O professor deve guiar os estudantes na leitura através dos textos, interagindo como seu tutor, devendo haver compartilhamento da leitura e interpretações.

A elaboração deve contemplar uma situação real que necessita ser investigada, de forma desafiadora, por meio de análise, interpretação crítica, levantamento de hipóteses, busca de suposições, síntese, argumentação e decisão. O professor tem o papel de selecionar o material, apresentar um roteiro de trabalho, orientar os grupos e, ao final, avaliar a atividade realizada (ANASTASIOU; ALVES, 2004).

Para possibilitar o cuidado em saúde, durante a formação do Técnico em Enfermagem, há o campo prático que propicia a interação do acadêmico com a vivência profissional enquanto agente cuidador, que o permite colocar em prática o conhecimento teórico adquirido a fim de integrar o que se compreende por cuidar (ANASTASIOU; ALVES, 2004).

As aulas práticas têm a finalidade de levar o estudante a aperfeiçoar a técnica sobre conhecimentos de uma determinada disciplina teórica. Logo, consistem em inserir o estudante em instituições de saúde para que neste local, acompanhado constantemente pelo docente, aprenda realizar procedimentos, técnicas e ver casos reais de estudos, até então vistos somente na teoria. Esse contato com os pacientes é imprescindível e deve permear a formação do profissional de enfermagem (RODRIGUES et al., 2015).

Outro fator importante no ensino é o planejamento, a definição de quais métodos serão utilizados para o desenvolvimento das atividades. Nesse contexto, Gil (2012, p. 94), reflete sobre a falta de criatividade com que muitos professores ainda planejam seus cursos "simplesmente seguem os capítulos de um livro-texto, sem considerar o que é realmente necessário que os estudantes aprendam". Além disso, o autor destaca que muitos professores também utilizam sempre os mesmos métodos de ensino e procedimentos de avaliação, não acompanhando assim as mudanças e evoluções que vêm ocorrendo.

\section{METODOLOGIA}

A pesquisa é do tipo exploratória e descritiva. A pesquisa exploratória é o tipo de pesquisa que tem em vista favorecer a familiaridade, o aumento da experiência e uma melhor compreensão do problema a ser investigado, já a pesquisa descritiva geralmente assume a forma de levantamento de dados ou ainda a forma de pesquisa bibliográfica e documental (CHEMIN, 2015). 
Quanto ao tipo de pesquisa apresenta uma abordagem quantitativa, tem como objetivo quantificar os dados e generalizar os resultados da amostra para a população-alvo; normalmente é usada para amostras com grande número de casos representativos; a coleta de dados é estruturada; a análise de dados é estatística e os resultados recomendam uma linha de ação final (CHEMIN, 2015).

A população estudada na pesquisa foram os estudantes do Técnico em Enfermagem de Guaporé, matriculados no segundo semestre de 2017. Participaram da pesquisa, 30 estudantes dos 35 matriculados na disciplina de Introdução à Enfermagem. A disciplina ocorreu no formato semipresencial, $50 \%$ presencial e $50 \%$ a distância.

O método adotado para a seleção dos sujeitos do estudo foi o não probabilístico por conveniência, considerando o critério de acessibilidade. Adotaram-se como critérios de inclusão: ser estudante do curso Técnico em Enfermagem em Guaporé, lócus da pesquisa e ser estudante efetivo na disciplina de Introdução à Enfermagem, no horário da sexta-feira à noite, no segundo semestre de 2017.

As informações foram coletadas no segundo período letivo, mais precisamente no mês de novembro a dezembro de 2017, mediante a utilização da técnica de questionário com perguntas abertas e fechadas.

As metodologias de ensino e aprendizagem listadas e pesquisadas no questionário foram baseadas na obra de Anastasiou (2004). A coleta de dados aconteceu em sala de aula, sendo as questões organizadas por meio do Google Formulários, com o link disponibilizado no ambiente virtual da Turma. Após, as respostas dos estudantes foram agrupadas e serão apresentadas em gráficos, para uma melhor compreensão, sendo tratadas quantitativamente. pesquisa.

A Figura 1 representa as fases que fizeram parte da metodologia da 
Figura 1 - Fluxograma representativo da Metodologia utilizada na Pesquisa.

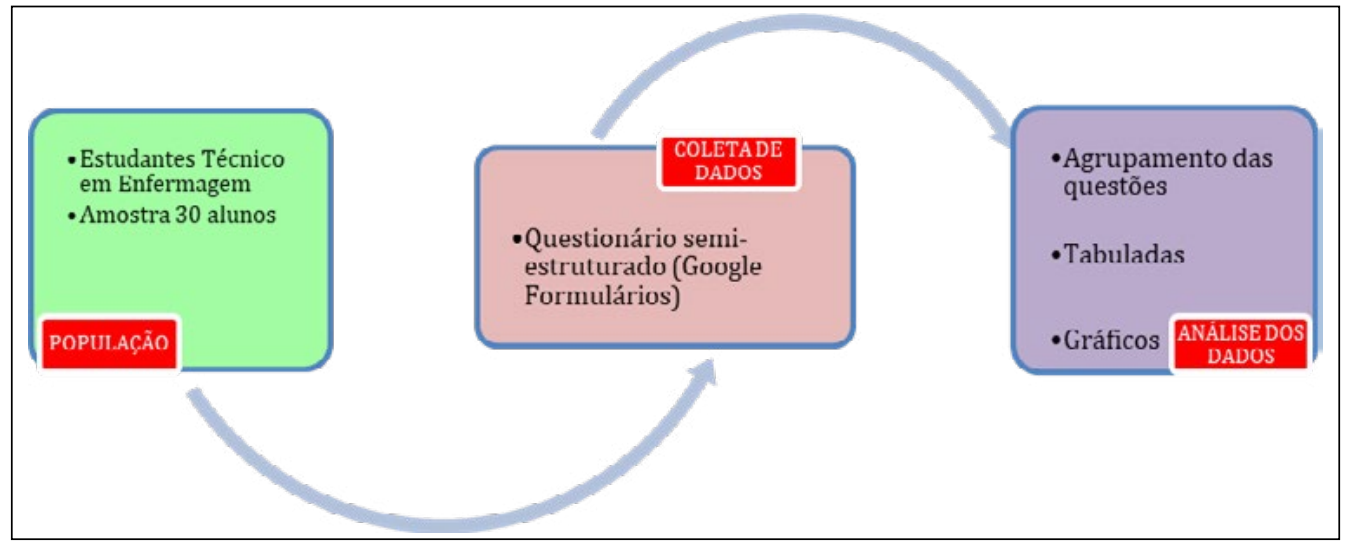

Fonte: Dos autores (2018).

\section{ANÁliSE E DISCUSSÃO DOS RESULTADOS}

Após a coleta, tabulou-se os dados em planilha do Microsoft Excel e gráficos foram organizados e formatados a partir destes resultados, para obter os percentuais de resposta de cada item, com o intuito de verificar a variação de opiniões entre as respostas das questões, conforme apresentado a seguir, por meio da análise destes resultados e apresentação destes gráficos.

\subsection{Perfil dos Estudantes Entrevistados}

Quanto ao perfil dos estudantes entrevistados, verificou-se que $81 \%$ são do sexo feminino e 19\% do gênero masculino. Quanto à faixa etária $40 \%$ dos entrevistados tinham entre 22 a 28 anos, 23\% acima de 29 anos até 35 anos, $20 \%$ de 18 até $21,17 \%$ acima de 35 anos e nenhum estudante menor de 18 anos. Então, podemos observar que à turma trata-se na sua maioria de adultos jovens de 22 a 28 anos, que provavelmente estão retornando aos estudos após estarem alguns anos fora de instituições escolares.

No questionário, uma das questões solicitava que os estudantes marcassem quais habilidades julgavam importantes que fossem desenvolvidas ao longo de sua formação para exercer a profissão de Técnico em Enfermagem. As respostas são apresentadas no Gráfico 1 e mostram que a maioria acredita que atitude ética com $30 \%$ das respostas, seguida da preparação técnica com $27 \%$ e apenas $2 \%$ indicou a liderança como habilidade importante para o técnico em Enfermagem.

Rodrigues et al (2014) confirma o resultado, referindo que a ética a serviço da vida diz respeito ao comprometimento com a vida humana em quaisquer condições, independentemente da fase do ciclo vital, do gênero a que pertença 
ou do posicionamento do cliente/paciente na pirâmide social, tratando-se de característica fundamental para exercer a profissão.

Gráfico 1 - Habilidades importantes para o Técnico em Enfermagem

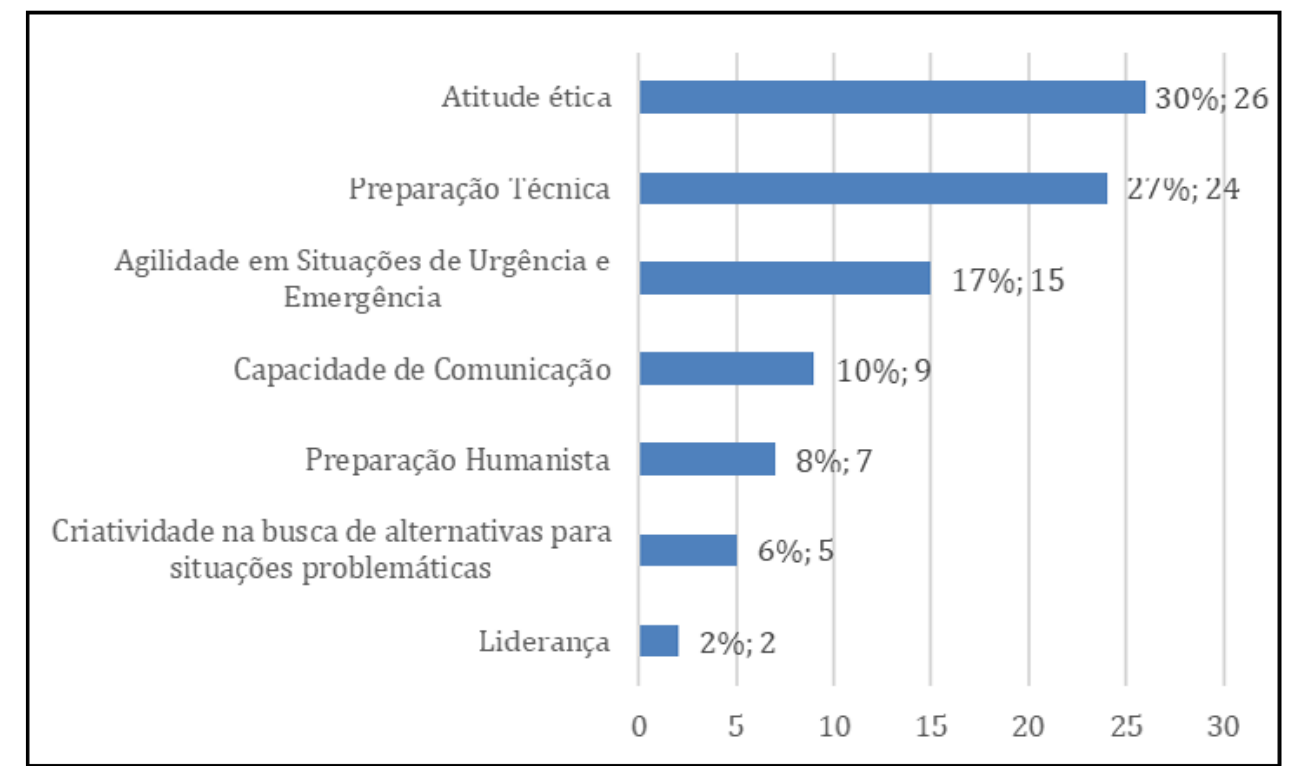

Fonte: Dos autores (2018).

O Gráfico 2 mostra os resultados em relação da questão que trata da avaliação da estrutura curricular do curso. Dos entrevistados $87 \%$ consideram que a estrutura curricular é adequada e suficiente e apenas 13\% disseram que era parcialmente adequada e suficiente.

Gráfico 2 - Qualidade da estrutura curricular do curso

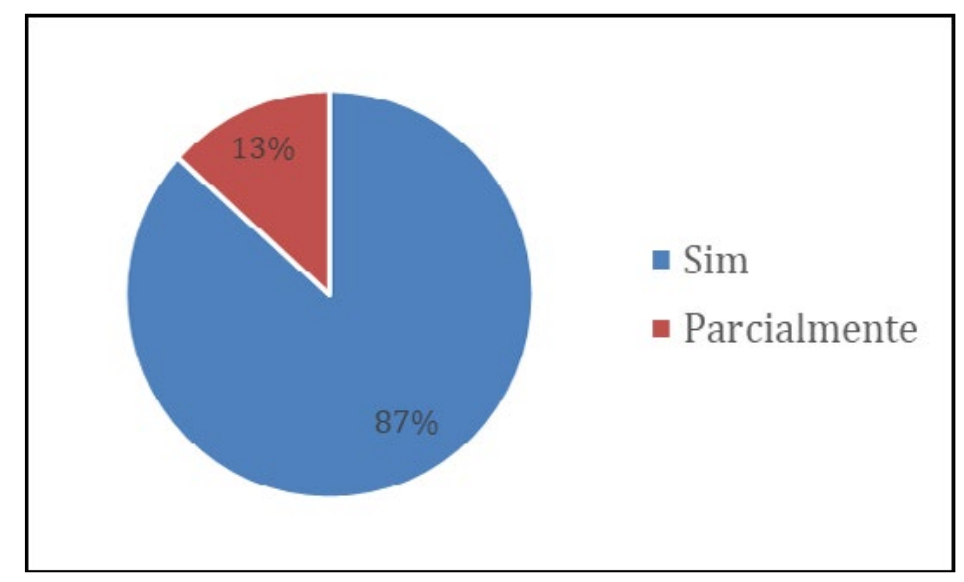

Fonte: Dos autores (2018). 
Pode-se concluir que, na avaliação em relação a matriz curricular, os estudantes aprovam a organização das disciplinas e respectivos conteúdos, o que parece confirmar que a curso de técnico em Enfermagem oferece uma boa estruturação das disciplinas, bem como uma integração de teorias e práticas adequadas.

\subsection{Uso das Metodologias na Avaliação dos Estudantes}

Sob o ponto de vista dos estudantes, são agora apresentados os resultados sobre as preferidas metodologias de ensino e aprendizagem utilizadas em sala de aula pelo professor da disciplina de Introdução à Enfermagem. Os resultados da investigação mostrados no Gráfico 3 indicam que as aulas que envolveram atividades práticas são das que mais gostam. Sob o ponto de vista dos estudantes com $24 \%$, seguida de aulas expositivas com $17 \%$.

O resultado corrobora com a observação de Manuel et al. (2016), ao afirmar que é necessário que os professores percebam a necessidade desses estudantes terem uma visão prática daquilo que lhes está sendo ensinado. Também é importante observar que, apesar das críticas que esta sofre, por ser centrada somente no professor, para $17 \%$ dos estudantes, a aula expositiva é uma metodologia de ensino eficaz para o aprendizado.

Gráfico 3 - Preferências dos estudantes das metodologias utilizadas na disciplina

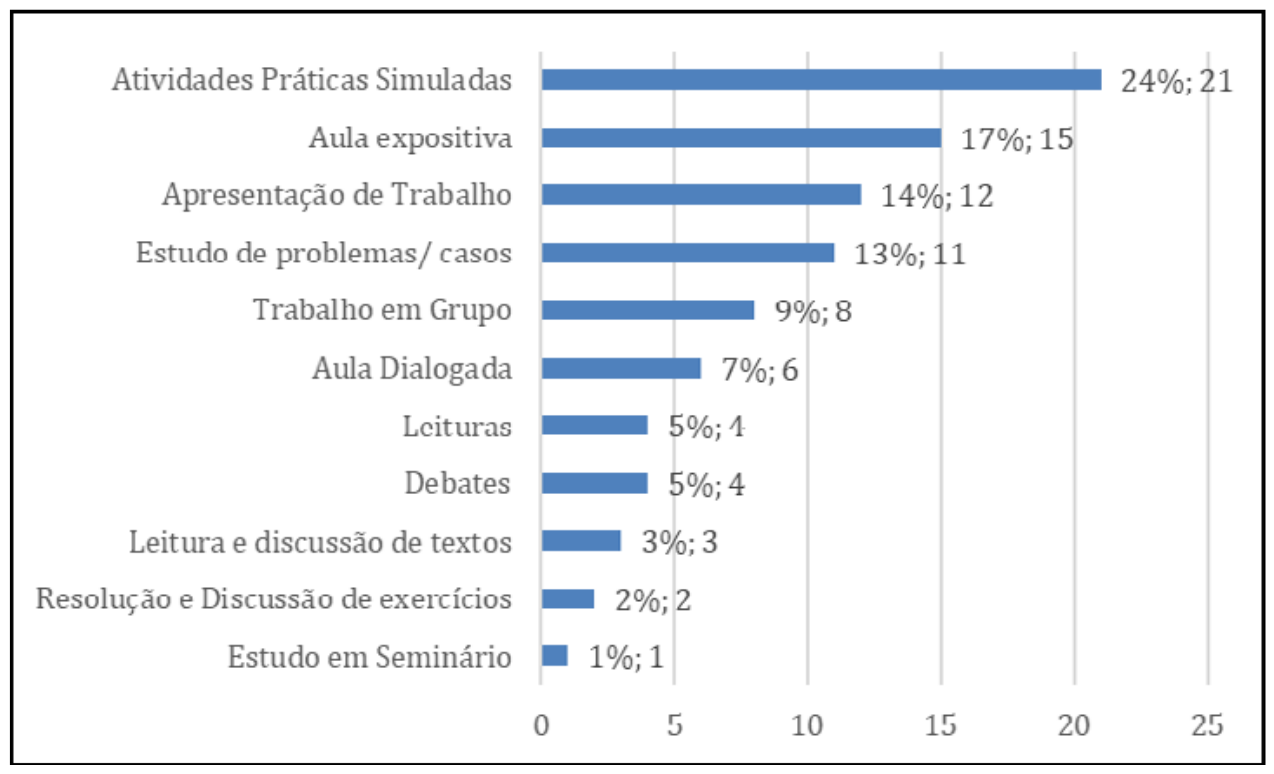

Fonte: Dos autores (2018).

Com relação às metodologias mais utilizadas por parte dos outros professores, de outras disciplinas do curso do Técnico em Enfermagem, os 
estudantes apontaram a apresentação de trabalho com $26 \%$, seguida de trabalho em grupo com $21 \%$.

Borges e Alencar (2014) confirmam que há extrema necessidade de trabalhos em grupo, um processo ativo de troca e produção de conhecimento, e não somente difusão de informações, um conhecimento apropriado e condizente com cada realidade. Sobre a apresentação de trabalhos pode-se inferir que a maior utilização pelos professores é devido à necessidade de envolvimento e participação dos estudantes no processo de construção da aprendizagem e pode-se dizer também devido à resistência de utilizar novas metodologias no ensino.

Quanto às metodologias mais utilizadas pelos professores no curso, podemos ver as opções mais selecionadas, de forma mais abrangente, no Gráfico 4.

Gráfico 4 - Metodologias mais utilizadas pelos professores de outras disciplinas do curso

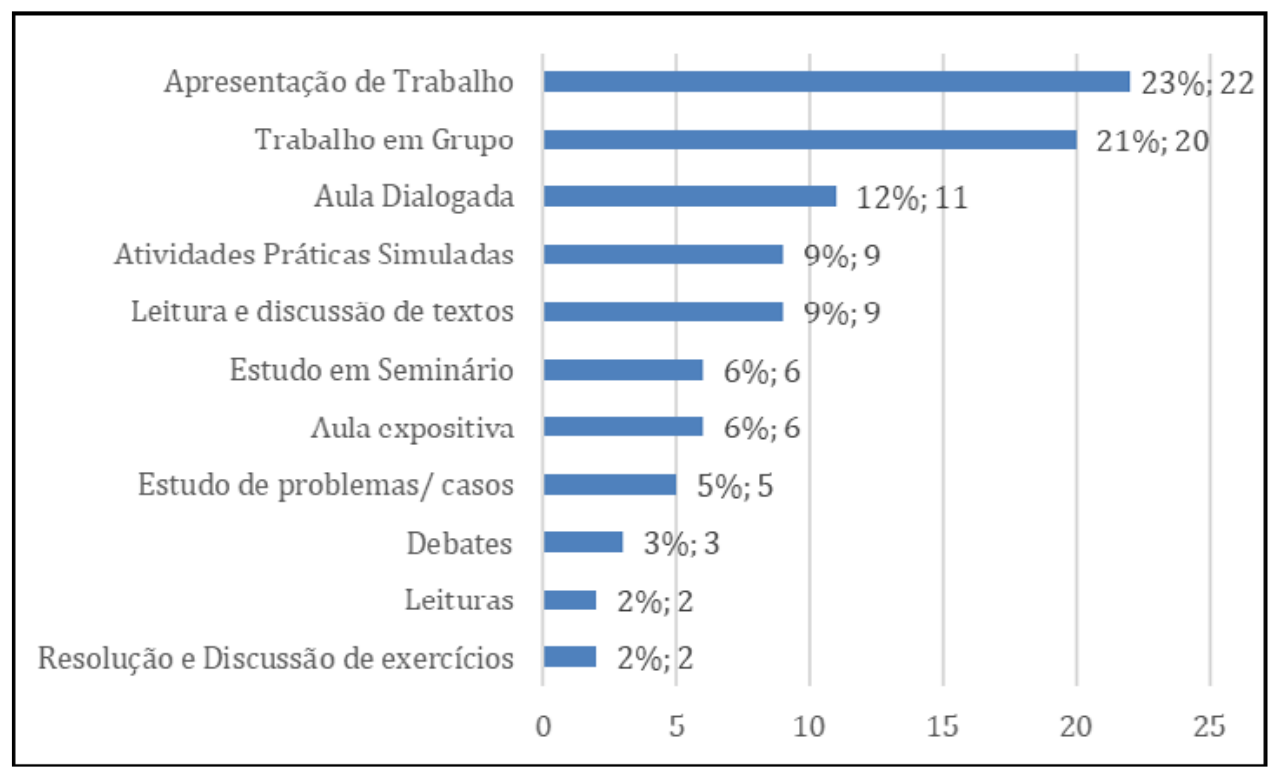

Fonte: Dos autores (2018).

Quanto à metodologia de aprendizagem os estudantes identificaram como a menos preferida Debates com 16\%, Trabalho em Grupo com 15\% e Leituras com $13 \%$. Nos dados apresentados no Gráfico 5 que referencia que as atividades práticas e os estudos de problemas/ caso são significativamente mais importantes quando comparados com debates e trabalhos em grupo. 
Gráfico 5 - Metodologias de aprendizagem menos preferidas pelos estudantes

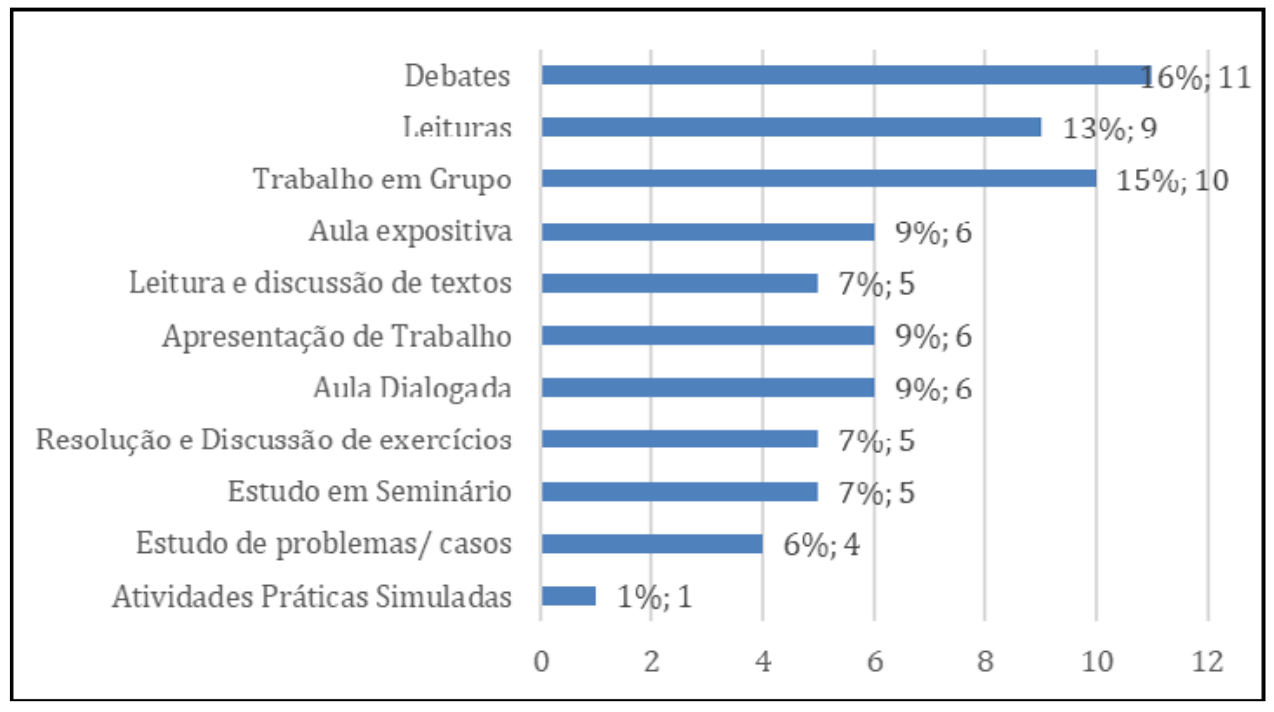

Fonte: Dos autores (2018).

Aqui podemos trazer a contribuição Manuel et al. (2016), que enfatizam que os professores precisam avaliar seu conteúdo programático das disciplinas, pois na matriz curricular deste curso, existem disciplinas com especificidades que exigem prática, na qual pode ser realizada, em ambientes ambulatoriais, uso de simuladores ou de outras formas. Porém é necessário, que os professores percebam a necessidade desses estudantes terem uma visão prática daquilo que lhes está sendo ensinado.

Quanto o uso das Metodologias de ensino e aprendizagem empregadas na disciplina de Introdução em Enfermagem, 20\% dos estudantes avaliou-as como ótimo, 50\% como muito bom e 30\% como bom. Pode-se considerar que os estudantes estão satisfeitos com o andamento das aulas e as metodologias aplicadas na disciplina, conforme resultados no Gráfico 6. 
Gráfico 6: Avaliação das metodologias utilizadas em Introdução em Enfermagem

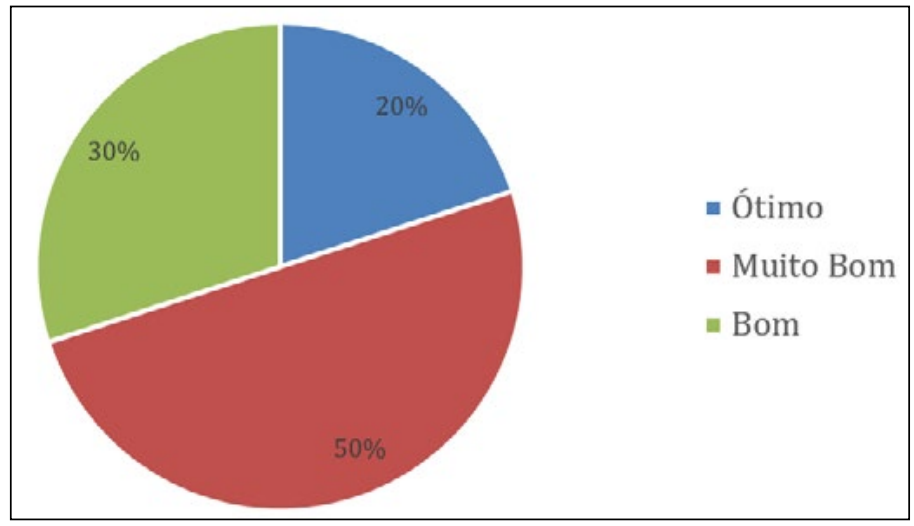

Fonte: Dos autores (2018).

Na questão aberta tratou-se de avaliar a disciplina, oportunizando aos estudantes relatarem os pontos positivos, negativos e sugestões em relação da disciplina de Introdução em Enfermagem. Na sequência serão apresentados os relatos considerados mais relevantes em relação a disciplina avaliada:

- "Pontos positivos como aula com aulas práticas, trabalhos apresentados em sala de aula; negativos são a pouco comunicação entre colegas, e pouco tempo para realizar algumas práticas";

- “Na minha opinião o ensino está sendo muito bom, mas seria melhor se tivesse mais aulas práticas"; esperava";

- "A metodologia está muito bem aplicada a disciplina dentro do que eu

- "O ambiente é bastante agradável, as aulas estão sendo aplicadas de forma mais natural e simples, porém com muito conteúdo. Acredito que cada dia que passa estão se tornando melhores";

- "Aulas presenciais são melhores que a distância";

- "Mais aulas práticas para discussão da disciplina, eu acho que com isso aprendemos mais".

Diante da livre manifestação dos estudantes, percebe-se a dificuldade que os estudantes manifestaram diante do aprendizado com a aplicabilidade da metodologia a distância, que foi oferecida em $50 \%$ na disciplina de Fundamentos em Enfermagem e também a ansiedade em realizar mais atividades práticas.

\section{CONCLUSÃO}

Por meio dos resultados deste estudo pretende-se estimular discussões para contribuir com o desenvolvimento do processo de ensino e de 
aprendizagem, uma vez que se constatou que o uso de novas metodologias no processo do conhecimento em enfermagem ainda está em construção, com o objetivo de formar profissionais da saúde como sujeitos crítico-reflexivos.

Identificar as metodologias de ensino utilizadas pelos docentes do curso Técnico em Enfermagem permitiu avaliar as diferentes metodologias que os mesmos utilizam em suas aulas e como estas são percebidas pelos estudantes no processo de ensino e aprendizagem, especificamente na disciplina de Introdução à Enfermagem.

Com o estudo ficou evidenciado que ensinar e aprender vai muito além do que transmitir e reproduzir conhecimentos. Considerando as novas metodologias na Educação, ficou entendido que o professor necessita atuar como mediador, motivar ideias, para que os estudantes se tornem ativos, críticos e reflexivos, evidenciando a prática profissional atual.

Diante deste cenário, sugere-se que a continuidade de pesquisas que retratem a avaliação dos métodos de ensino, e com isso contribuir com aprendizagem dos estudantes do ensino técnico, confrontando os resultados com as percepções e opiniões de docentes e estudantes.

\section{REFERÊNCIAS}

ANASTASIOU, L. G. C.; ALVES, L. P. Estratégias de Ensinagem. Cuiabá:

Universidade Federal do Mato Grosso, 2004. Disponível em: https:/ / edisciplinas.usp. br/pluginfile.php/1949509/mod_resource/content/1/Cap.3\%20-\%20Processos $\% 20$ de\%20Ensinagem\%20-\%20Anastasiou.pdf. Acessado em: 06 jan. 2018.

BASTOS, C. C. Metodologias ativas. 2006. Disponível em: <http:/ / educacaoemedicina.blogspot.com.br/2006/02/metodologias-ativas.html>. Acessado em: 06 jan. 2018.

BERBEL, N. A. N. A problematização e a aprendizagem baseada em problemas: diferentes termos ou diferentes caminhos? Interface Comun Saúde Educ [serial on the internet]. 1998. Disponível em: http://www.scielo.br/pdf/icse/v2n2/08.pdf. Acessado em: 10 jan. 2018.

BORGES, T. S.; ALENCAR G. Metodologias ativas na promoção da formação crítica do estudante: $o$ uso das metodologias ativas como recurso didático na formação crítica do estudante do ensino superior. Cairu em Revista. Ano 03, n. 04, p. 119-143, Jul/Ago 2014. >. Disponível em: https://pt.scribd.com/document/283337905/08Metodologias-Ativas-Na-Promocao-Da-Formacao-Critica-Do-Estudante. Acessado em: 26 fev. 2018.

BRASIL, Ministério da Educação e Cultura (BR). Referenciais curriculares nacionais da educação profissional de nível técnico. Brasília (DF): PROEP; 2000.

BRASIL. CONSTITUIÇÃO DA REPÚBLICA FEDERAL DO BRASIL DE 1988. Lei de Diretrizes e Bases da Educação. Lei n.9.394 de 20/12/1996. 
BRASIL. Ministério da Educação. Conselho Nacional de Educação. Parecer CNE/CEB n. 16/99. Dispõe sobre as Diretrizes Curriculares para a Educação Profissional de Nível Técnico [legislação na Internet]. Brasília; 1999. Disponível em: <http:/ / portal. mec.gov.br/setec/arquivos/pdf_legislacao/tecnico/legisla_tecnico_parecer1699. pdf $>$. Acessado em: 21 jan. 2018.

CASTANHA, E. T.; MONTEIRO, J. J.; CITTADIN, A.; GIASSI, D.; GUIMARAES, M. L. F. Metodologias Ativas de Aprendizagem e a Promoção da Autonomia dos Estudantes de Ciências Contábeis. In: II Congresso de Contabilidade da UFRGS, 2017, Porto Alegre, 2017. Disponível em: <https: / /www.ufrgs.br/congressocont/ index.php/congresso/congressocont/paper/view/33>. Acessado em: 20 fev. 2018.

CHEMIN, Beatris Francisca. Manual da Univates para trabalhos acadêmicos: planejamento, elaboração e apresentação. 3.ed. Lajeado: Univates, 2015.

FERNANDES, E. (1983). O estudante e o professor na escola moderna. Porto: Tecnilivro.

FREIRE, Paulo. Educação e Mudança. 12. ed. Rio de Janeiro. Paz e Terra. Rio de Janeiro, 1979.

GIL, A. C. Didática do Ensino Superior. São Paulo: Atlas, 2012.

LIBÂNEO, J. C. Didática. São Paulo: Cortez, 1994.

LOPES, J., SILVA, H. (2009). A aprendizagem cooperativa na sala de aula: Um guia prático para o professor. Lisboa: Lidel.

MACHADO, T. (Org). Educação 2006 - As mais importantes tendências na visão dos mais importantes educadores. Curitiba: Humana editorial, 2006.

MANUEL, K. B. et al, Metodologias de ensino em contabilidade: percepção de discentes brasileiros e angolanos. Departamento de Ciências Contábeis e Autuariais. Brasília, 2016. Disponível em: <http:/ / soac.unb.br/index.php/ccgunb/ccgunb2/ paper/viewFile/5389/1446>. Acessado em: 25 mar. 2018.

MARTINS, J Didática Geral. 2.ed. São Paulo: Atlas, 1990.

MINAYO M.C. O desafio do conhecimento: pesquisa qualitativa em saúde. Rio de Janeiro: Abrasco; 2007.

MITRE, Sandra M. et al. Metodologias ativas de ensino-aprendizagem na formação profissional em saúde: debates atuais. Ciência \& Saúde Coletiva, Rio de Janeiro, v. 13, supl. 2, p. 2.133-2.144, 2008. Disponível em: <www. scielo.br/pdf/csc/v13s2/ v13s2a18.pdf >. Acessado em: 20 mar. 2018.

MORAN, J. M. Mudando a educação com metodologias ativas. 2013. Disponível em: <http://www2.eca.usp.br/moran/wp-content/uploads/2013/12/mudando_moran. pdf>. Acessado em: 22 fev. 2018. 
MORAN, José, Metodologias Ativas para uma aprendizagem mais profunda.

Coleção Mídias Contemporâneas. Convergências Midiáticas, Educação e Cidadania: aproximações jovens. Vol. II. Carlos Alberto de Souza e Ofelia Elisa Torres Morales (orgs.). PG: Foca Foto-PROEX/UEPG, 2015. Disponível em: <http:/ / www2.eca.usp. $\mathrm{br} / \mathrm{moran} / \mathrm{wp}$-content/uploads/2013/12/metodologias_moran1.pdf $>$. Acessado em: 21 jan. 2018.

MOREIRA, J. R., RIBEIRO, J. B. P; Prática Baseada em Metodologia Ativa: Aprendizagem sob a Perspectiva do letramento informacional para o Ensino na Educação Profissional. Periódico Científico Outras Palavras, volume 12, número 2, ano 2016, página 95 a 114. Disponível em: <http:/ / revista.faculdadeprojecao.edu.br/ index.php/Projecao5/article/view/722>. Acessado em: 11 jan. 2018.

OLIVEIRA, Djalma de Pinho Rebouças; Planejamento Estratégico. 26a ed, São Paulo: Atlas, 2009.

PEREIRA, A. L. F. As tendências pedagógicas e a prática educativa nas ciências da saúde. Caderno de Saúde Pública. 2003. Disponível em: <http:/ / www.scielo.br/pdf/ csp/v19n5/17825.pdf>. Acessado em: 22 jan. 2018.

RODRIGUES, J. Z. et al, A Importância da Aula Prática na Formação do Profissional de Enfermagem: um relato de experiência. Revista Panorâmica On-Line. Barra do Garças - MT, vol. 19, p. 99 - 110, ago./dez. 2015. Disponível em: <http:/ / revistas.cua. ufmt.br/index.php/revistapanoramica/article/viewFile/629/252>. Acessado em: 10 jan. 2018.

SANTOS, S.C. O processo de ensino-aprendizagem e a relação professor-estudante: aplicação dos "sete princípios para a boa prática na educação de ensino superior". Cad Pesq. Administração 2001; 8(1): 69-75. Disponível em: <http:/ / www.sinprodf. org.br/wp-content/uploads/2012/01/tx_5_proc_ens_aprend.pdf $>$. Acessado em: 10 jan. 2018.

SILVA M.C.N. MACHADO, M. H. Perfil da Enfermagem, COFEN e FIOCRUZ. 2015. Disponível em: <http:/ / www.cofen.gov.br/perfilenfermagem>. Acessado em: 20 jan. 2018.

SILVA, EM, MORAIS MJB. Avaliação da Aprendizagem: pressupostos ideológicos de uma prática de avaliação na Educação de Jovens e Adultos [dissertação na Internet]. Belém (PA): Universidade da Amazônia; 2002. Disponível em: <http:/ / www.nead.unama.br/site/bibdigital/monografias/avaliacao_da_aprendizagem. pdf $>$. Acessado em: 06 jan. 2018.

\section{ZANOTTI, Renzo. Expandindo as Fronteiras da Educação em Enfermagem}

Globalmente. Vol. 4. Ribeirão Preto - SP: Revista Latino Americana em Enfermagem.1996. Disponível em: <http:/ / www.scielo.br/scielo.php?script=sci arttext\&pid=S0104-11691996000100016> . Acessado em: 22 fev. 2018. 